\title{
Post Operative Outcome of Superior \& Temporal Incision in Manual Small Incision Cataract Surgery
}

\author{
Krishnadeo Vishnu Nalavade ${ }^{1}$, Smita Dileep Javadekar ${ }^{2}$ \\ ${ }^{1}$ Associate Professor, Department of Ophthalmology, PIMS \& R Islampur Maharashtra, 2Professor, Department of \\ Ophthalmology, KIMS deemed to be University, Karad, Maharashtra, India
}

Corresponding author: Dr. Krishnadeo Vishnu Nalavade, M.S.(Ophthalm), Aditya, Omkar colony, Peth - Sangli Road, Islampur, Tal.- Walwa, Dist. - Sangli Maharashtra 415409, India

DOI: http://dx.doi.org/10.21276/ijcmsr.2020.5.1.20

(c) BY-NC-ND

How to cite this article: Krishnadeo Vishnu Nalavade, Smita Dileep Javadekar. Post operative outcome of superior \& temporal incision in manual small incision cataract surgery. International Journal of Contemporary Medicine Surgery and Radiology. 2020;5(1):A88-A91.

\section{A B S T R A C T}

Introduction: Incision site has a significant effect on surgical outcome. It is seen that temporal incisions cause less astigmatism than superior incisions. So site of incision is important. The aim of the present study was to observe outcome of superior and temporal incision on postoperative astigmatism in manual small incision cataract surgery (SICS) cases.

Material and Methods: 100 patients of cataract were included in the Combined Study at PIMS Islampur and KIMS Karad (50 Patients each). Both with the rule (WTR) and against the rule (ATR) astigmatism were included in the study. The astigmatic status and the comparative impact of site of scleral incision on astigmatism were studied. A comparative study was done in which patients were divided into two groups. SICS was performed with superiorly placed incision in group I and temporally placed incision in group II.

Results: Amongst the total 100 patients undergoing SICS, 53 patients had ATR, 35 patients had WTR and 10 patients were not having any type of astigmatism. Thus the pre-operative astigmatic status shows that ATR is more common type of astigmatism.Among 50 patients in which superior incision was taken, 20 had pre-operative WTR, 27 had ATR and 3 did not have astigmatism. Postoperatively the number of patients with WTR decreased to 12 , the number. of patients with ATR increased to 32 \& 6 had no astigmatism suggesting that superior (upper) incision decreases vertical axis and increases the horizontal axis causing ATR change. Among 50 patients in temporal incision group, 20 had pre-operative WTR, 29 had ATR and 1 did not had astigmatism. Post operatively the number of patients with WTR increased to 26, the number of patients with ATR decreased to 20 \& 4 did not had astigmatism.

Conclusion: During SICS incision on steep corneal axis reduces pre-existing astigmatism. Thus in ATR astigmatism it is taken temporally and in WTR astigmatism it is taken superiorly. Thus a incision site has significant role in reducing post surgical astigmatism.

Keywords: Cataract, Surgery, Astigmatism, Incision, Diopter

\section{INTRODUCTION}

Cataract surgery is now a days considered as a refractive surgery. Improvement in surgical skill in the cataract surgery has raised the patient's expectations regarding visual outcome. Spectacleless good postoperative vision is considered the normal. ${ }^{1}$ Less amount of postoperative astigmatism will meet these expectations

Today's cataract surgery is not only removal of cataract followed by Intra Ocular Lens (IOL) implantation but also the best spectacleless visual acuity. It is not only blind rehabilitation. It definitely gives normal vision.

Manual Small Incision Cataract Surgery and Phacoemulsification with posterior chamber intraocular lens implantation are today's most common surgeries for cataract. Phacoemulsification is the most favoured method in the developed countries. In the developing countries like India, manual small incision cataract surgery is the most popular method, as the machinery for phacoemulsification is expensive and it requires maintenance. It has a steep learning curve also ${ }^{6}$

Manual small incision cataract surgery (SICS) through a sclerocorneal tunnel is the procedure gives advantages of sutureless wound closure with less astigmatism at low cost. Several variables are there in the construction of wound of cataract surgery like location, direction, width, depth and shape. Site of incision makes too much difference on postoperative astigmatism. It has been studied that horizontal scleral (temporal) incision induce less astigmatism than vertical scleral (superior) incision signifying the importance of scleral incision site.

The temporal location is away from the visual axis and any flattening due to the wound less likely affects the corneal curvature at the visual axis. When the incision is superior, gravity and eyelid blink cause a drag on the incision. Gravity 
\& eyelid blink forces are neutralised by temporal incisions because the incision is parallel to the vector of the forces. As most elderly cataract patients have preoperative against the rule astigmatism,with the rule astigmatism induced by a temporal incision is advantageous. ${ }^{1}$

Thus temporal incisions induce less astigmatism than superior incisions indicating the importance of incision location.

Our study was conducted to study the effect of site of scleral incision on existing astigmatism and post- operative astigmatism.

The aim and objectives of the study were to compare existing astigmatism and post-operative astigmatism and to study the effect of site of incision on preoperative astigmatism and to surgically induced astigmatism.

\section{MATERIAL AND METHODS}

This was study done on 100 patients undergoing manual small incision cataract surgery at PIMS, Islampur \& KIMS, Karad.

\section{Inclusion criteria}

1. With the rule astigmatism (WTR).

2. Against the rule astigmatism (ATR).

\section{Exclusion criteria}

1. Irregular astigmatism.

2. Corneal dystrophies and degenerations.

3. Traumatic Cataract

Detailed study of the cases including keratometry, slit lamp biomicroscopy examination of anterior segment, retinal examination with indirect ophthalmoscopy and direct ophthalmoscopy were done. A- Scan biometry was done to calculate IOL power. The incision was taken on the steep axis where the astigmatism was $>1 \mathrm{D}$ either superiorly or temporally. SICS was performed in both the groups.

\section{Procedure}

Preliminary preparation of the eye for surgery was done. Conjunctival flap was taken at superiorly or temporally accordingly. Catuery was done. Scleral incision (frown

\begin{tabular}{|l|c|}
\hline Type of astigmatism & No. of patients \\
\hline WTR & 40 \\
\hline ATR & 56 \\
\hline No astigmatism & 4 \\
\hline \multicolumn{2}{|c|}{ Table-1: Existing astigmatic status of cataract patients. } \\
\hline
\end{tabular}

shaped) was taken $2 \mathrm{~mm}$ behind the limbus superiorly or temporally. Size of the incision was about $6 \mathrm{~mm}$. Sclerocorneal tunnel was performed by crescent knief $1.5 \mathrm{~mm}$ inside the cornea. Side port incision was made at 1', 10' or 7' o clock position according to temporal or superior incision. Anterior chamber was filled with Viscoelastic and continuous curvilinear capsulorrhexis was done with cystitome through side port. With $3.2 \mathrm{~mm}$ keratome Sclerocorneal tunnel was completed and extended upto $6-6.5 \mathrm{~mm}$. Internal corneal incision was extended $1-2 \mathrm{~mm}$ more than external incision. Nucleus was prolapsed into the anterior chamber after careful hydrodissection. Nucleus was coated anteriorly and posteriorly by injecting enough amount of viscoelastic Nnucleus was brought out using sandwich technique with the use of vectis and Sinskey Hook. Cortical clean up was done by Simcoe cannula. PMMA single piece posterior chamber lens ( $6 \mathrm{~mm}$ optic with overall $12.5 \mathrm{~mm}$ ) was implanted in the capsular bag. Viscoelastic was removed.Anterior chamber was formed with BSS through the sideport with Simcoe cannula. The scleral incision was checked for any leakage and then conjunctiva was reposed and fixed using cautery.

Post-operatively topical steroid \& antibiotic combination for a week was given followed by topical steroid only which was tpapered over for 6 weeks. Vision, slit lamp examination and keratometric examinations were done on 1 st postoperative day, 1 week, 6 weeks and 3 months postoperatively.

Astigmatic changes only in the vertical \& horizontal meridian were studied for convinience. Oblique astigmatism was not studied. Readings of two groups were compared with regard to post-operative astigmatism. By subtraction method analysis of astigmatism was done.

Paired and unpaired $t$ test were applied to find out the significant difference between the superior and temporal incisions.

\section{RESULTS}

The preoperative astigmatic condition of patients shown in Table 1 shows that the number of patients with WTR is 40, ATR is 56 and without any astigmatism is 4 (Table 1).

The preoperative astigmatic condition in WTR in superior incision is 20 and postoperative is 12 . The preoperative astigmaticcondition in WTR in temporal incision is 20 and postoperative is 26 . The preoperative astigmatic condition in ATR in superior incision is 27 and postoperative is 32.the preoperative astigmatic condition in ATR in temporal

\begin{tabular}{|l|c|c|c|c|}
\hline \multirow{2}{*}{ Type of astigmatism } & \multicolumn{2}{|c|}{ Superior incision } & \multicolumn{2}{c|}{ Temporal incision } \\
\cline { 2 - 5 } & Pre-Existing & Post-Surgical & Pre-Existing & Post-Surgical \\
\hline WTR & 20 & 12 & 20 & 26 \\
\hline ATR & 27 & 32 & 29 & 20 \\
\hline No astigmatism & 3 & 6 & 1 & 4 \\
\hline \multicolumn{2}{r|}{ Table-2: Existing astigmatic Status in Upper Scleral (superior) and Lateral Scleral (temporal) incision groups. } \\
\hline
\end{tabular}

\begin{tabular}{|l|c|c|c|}
\hline & Superior incision & Temporal incision & P-Value \\
\hline Mean preoperative astigmatism (D) & $1.25+/-0.5$ & $0.75+/ 0.35$ & $\mathrm{P}=0.907$ \\
\hline Mean post-Surgical astigmatism (D) (6 wks) & $1.75+/ 1.25$ & $0.5+/-0.35$ & $\mathrm{P}<0.0001$ \\
\hline Mean SIA (D) & $0.95+/-0.5$ & $0.60+/-0.5$ & $\mathrm{P}<0.0001$ \\
\hline \multicolumn{2}{|c|}{ Table-3: Pre and post-surgically induced astigmatism in superior and temporal incision groups. } \\
\hline
\end{tabular}




\begin{tabular}{|l|c|c|}
\hline & Mean Existing Astigmatism & Mean Post Surgical Astigmatism \\
\hline Upper scleral (superior) incision & $0.81+0.65$ & $1.50+0.5$ \\
\hline Lateral scleral (temporal) incision & $1.45+0.5$ & $1.05+0.2$ \\
\hline \multicolumn{2}{|c|}{ Table-4: Change in astigmatism in ATR cases. } \\
\hline
\end{tabular}

\begin{tabular}{|l|c|c|}
\hline & Mean Pre- Existing Astigmatism & Mean Post- Surgical Astigmatism \\
\hline Upper scleral (superior) incision & $1.15+/ 1.25$ & $0.75+/-0.5$ \\
\hline Lateral scleral (temporal) incision & $0.65+/-0.25$ & $1.00+/-0.5$ \\
\hline \multicolumn{2}{|c|}{ Table-5: Change in astigmatism in WTR cases } \\
\hline
\end{tabular}

incision is 29 and postoperative is 20 (Table 2).

The mean preexisting astigmatism in upper scleral (superior) incision is 1.25 and postsurgical astigmatism is 1.75 . The mean preexisting astigmatism in Lateral Scleral (temporal) incision is 0.75 and postsurgical astigmatism is 0.50 (Table $3)$.

The change in astigmatism in ATR and WTR group is shown in table 4 and 5 respectively. The mean astigmatism in upper scleral (superior) incision increased from 1.25 to 1.75 post surgically and in the lateral scleral (temporal) incision group the mean astigmatism decreased from 0.75 to 0.5 post operatively.

\section{DISCUSSION}

Though phacoemulsification is the most advanced and technically superior method of cataract surgery, it is not cost effective \& not convinent. SICS is alternative choice to phacoemulsification. Most of the advantages of "phacoemulsification" visual results are equivalent to small incision cataract surgery at a lower cost. It is the catract operation for more number of patients an for poor countries. The SICS catract operation is less economic, reqiures less time, safe and easy to learn for surgons and needs few equipments. However, increase in size of scleral incision induces greater astigmatism than phacoemulsification. More amount of astigmatic refraction is important cause of less visual acuity after cataract surgery. In view of this comparative study was done with the aim to study the comparative effect of scleral incision on existing and post surgical astigmatism.

In our study out of the total 100 patients undergoing SICS, 56 patients had ATR, 40 patients had WTR and 4 patients had no astigmatism. Thus the pre-operative astigmatic state shows that ATR is more common type of astigmatism in this group of patients undergoing cataract surgery group. ${ }^{1,8}$ This is because in normal healthy eyes stiff upper tarsal plate causes pressure on cornea resulting in with the rule astigmatism but with increasing age this pressure gradually decreases resulting in against the rule astigmatism.

In our study, based on the pre-operative keratometric values, the incision was taken on the steep axis where the astigmatism was $>1 \mathrm{D}$. In cases where the astigmatism was $<1 \mathrm{D}$, the incision was taken either superiorly or temporally. As we know from the review of literature on relation between location of incision and astigmatism, taking the incision on flat axis increases the astigmatism and if it is taken on the steep axis it decreases the astigmatism. Therefore in cases where the astigmatism was $>1 \mathrm{D}$, incision was taken on the steep axis to avoid further increase in the amount of astigmatism.

Among 50 patients in superior incision group, 20 had preoperative WTR, 27 had ATR and 3 did not have astigmatism. Post surgicaly the number of patients with WTR decreased to 12 , the number of patients with ATR increased to 26 showing that superior incision flattens vertical meridian and steepens the horizontal meridian causing ATR shift. $^{2}$

Among 50 patients in temporal incision group, 20 had preoperative WTR, 29 had ATR and 1 did not have astigmatism. Post surgicaly the number of patients with WTR increased to 26 , the number of patients with ATR decreased to 20. This shows that temporal incision flattens horizontal meridian and steepens the vertical meridian causing WTR shift. ${ }^{3,9}$

This is due to the fact that decrease in vertical corneal dimeter occurs at direction right angles to direction of cataract incisions. During healing of cornea scleral wound fibrous tissue proliferates, and after healing fibrous tissue contracts, therefore, upper scleral incision decreases vertical diameter of cornea and increases and horizontal diameter of cornea Therefore, superior incision flattens vertical meridian and steepens horizontal meridian. Temporal incision flattens horizontal meridian and steepens vertical meridian. This effect is more marked in the superior incision than temporal incision as the superior incision is closer to the visual axis than temporal incision.

In our study the mean Pre-Existing astigmatism in upper scleral (superior) incision group was $0.85+/-0.75$ which increased to $1.5+/-1.15$ post operatively. The mean postsurgical astigmatism in temporal incision group was $0.65+/-$ 0.35 which decreased to $0.50+/-0.35$ post operatively. Thus the post-operative astigmatism is more in upper scleral (superior) incision group than temporal incision group. Our study shows that there is no statistically significant difference in the mean pre-operative astigmatism in superior $(0.85+/-0.75)$ and temporal incision $(0.65+/-0.35)$ groups $(\mathrm{p}=0.907) .4,10$ There is a statistically significant difference between the superior and temporal incision in post-surgical astigmatism temporal incision ( $p<0.0001)$ This is because farther the incision from the visual axis less is the flattening effect on corneal curvature. Temporal incision is farther from the visual axis than the superior incision because the corneal diameter is greater in horizontal meridian than vertical meridian.

In our study change in astigmatism in cases with ATR shows that in upper scleral (superior) incision group the mean astigmatism increased from $0.81+/-0.65$ to $1.50+/-$ 0.5 post operatively and in the temporal incision group the 
mean astigmatism decreased from $1.45+/-0.5$ to $1.05+/-0.2$ post operatively. Thus in cases with ATR the upper scleral (superior) incision showed an increase in post-surgical astigmatism while a temporal incision showed decrease in astigmatism. $^{2}$

In our study change in astigmatism in cases with WTR shows that in upper scleral (superior) incision group the mean astigmatism decreased from $1.15+/-0.6$ to $0.70+/-$ 0.5 post operatively and in the temporal incision group the mean astigmatism increased from $0.65+/-0.5$ to $0.75+/-0.5$ post operatively. 3 Thus in cases with WTR the upper scleral (superior) incision showed an decreased in post-operative astigmatism while a temporal incision showed a minimal increase in astigmatism. ${ }^{6,7}$

This shows that taking the incision on flat axis increases the astigmatism and if it is taking on the steep axis it decreases the astigmatism. Thus only change in the site of incision can be a factor to minimize the pre-existing astigmatism and reduce the SIA.

\section{CONCLUSION}

It is observed that Pre-existing ATR is more common type of astigmatism than WTR and in older age group astigmatically neutral cases are seen.

Upper scleral (superior) incision causes ATR shift and temporal incision causes WTR shift. upper scleral (temporal) approach in MSICS produces less postoperative astigmatism compared to superior incision. Placement of incision on steep axis reduces preexisting astigmatism. Thus in ATR astigmatism it is placed temporally and in WTR astigmatism it is placed superiorly.

Thus a simple modification in incision placement can minimize surgically induced astigmatism and reduce preexisting astigmatism. Hence it is advised that all cataract surgeons should familiarize with temporal incision in cataract surgery

\section{ABBREVATIONS}

WTR - With the rule astigmatism, ATR-Against the rule astigmatism, SICS- Small Incision Cataract Surgery, DDiopter

\section{REFERENCES}

1. Gokhale NS, Sawhney S. Reduction in astigmatism in manual small incision cataract surgery through change of incision site. Indian J Ophthalmol. 2005;53(1):201-3.

2. Magdum RM, Gahlot A, Maheshgauri RD, Khevna P. A comparative study of surgically induced astigmatism in superior and temporal scleral incision in manual small incision cataract surgery. National Journal of Medical Research. 2012;2(4):497.

3. Alam J, Bhattacharjya H, Roy A, Das R, Gupta S, Bhattacharya U, et al. A Comparative Study of PostOperative Astigmatism in Superior versus Temporal Approach of Manual Small Incision Cataract Surgery". Journal of Evolution of Medical and Dental Sciences. 2014;3(26):7087-90.

4. Mallik VK, Kumar S, Kamboj R, Jain C, Jain K, Kumar S. Comparison of astigmatism following manual small incision cataract surgery: superior versus temporal approach. Nepal J Ophthalmol. 2012;4(2):343.

5. Radwan AA.Comparing Surgical-Induced Astigmatism through Change of Incision Site in Manual Small Incision Cataract Surgery (SICS). J Clinic Experiment Ophthalmol. 2011;2(4):161.

6. Pawar VS, Sindal DK. A comparative study on the superior, supero-temporal and the temporal incisions in small incision cataract surgeries for postoperative astigmatism. Journal of Clinical and Diagnostic Research. 2012;6(6):1229-32.

7. Oshika T, Samejima T, Miyata N. Calculation of surgically induced astigmatism. Nihon Ganka Gakkai Zasshi. 1995;99(8):901-9.

8. Yadav H, Rai V. A Study of Comparison Astigmatism Following Manual Small Incision Cataract Surgery: Superior versus Temporal Approach. Journal of Evolution of Medical and Dental Sciences. 2014;3(23):6430-4.

9. Koch PS: Structural analysis of cataract incision construction. J Cataract Refractive Surgery. 1991;117(Suppl-1):677-88.

10. Ernest PH, Lavery KT, Kiessling LA. Relative strength of scleral tunnel incisions with internal corneal lips constructed in cadaver eyes. J Cataract Refract Surg. 1993;19(3):457-61

\section{Source of Support: Nil; Conflict of Interest: None}

Submitted: 27-10-2019; Accepted: 21-01-2020; Published online: 17-02-2020 